\title{
COMPARISON OF METHODS FOR DETECTING SPECIFIC IgM ANTIBODY IN INFANTS WITH CONGENITAL RUBELLA
}

\section{J. R. Pattison*, Carolyn M. Jackson, Jennifer A. Hiscock,}

J. E. CRADOCK-Watson $\dagger$ AND Margaret K. S. RIDEHalgh $\dagger$

Department of Virology, The London Hospital Medical College, Turner Street, London EI 2AD, and $\nmid$ Public Health Laboratory, Withington Hospital, Manchester M20 8LR

CONGENITAL rubella can be diagnosed by finding specific IgM antibody in the serum of infected infants. Bellanti et al. (1965) separated the IgM-containing fraction of the serum by gel filtration through Sephadex G-200 and used a neutralisation test to demonstrate specific antibody. Vesikari et al. (1969) fractionated sera by centrifugation on sucrose density gradients and examined the IgM fractions for antibody by the haemagglutination-inhibition (HI) test. Cradock-Watson, Ridehalgh and Chantler (1976) also used the gradientfractionation technique but found indirect immunofluorescence to be more sensitive than $\mathrm{HI}$ for detecting antibody. They also found that antibody could be demonstrated more successfully by staining fractions than by staining whole serum.

The sensitivity of the HI test for rubella IgM antibody can be increased by allowing the serum fraction to react with antigen overnight at $4^{\circ} \mathrm{C}$ (long method), instead of for $1 \mathrm{~h}$ at room temperature (short method) (Pattison and Dane, 1975; Pattison and Mace, 1975). In the present study we compared six procedures for detecting IgM antibody in infants with congenital rubella, involving the separation of the IgM-containing fractions of their sera by sucrose densitygradient centrifugation or by gel filtration through Sephadex G-200 and then testing for specific antibody by both the long- and short-incubation HI methods, as well as by indirect immunofluorescence.

\section{MATERIALS AND METHODS}

Serum samples. Samples were collected from three groups of infants.

Group 1 consisted of 14 babies with congenital rubella, confirmed by virus isolation or by the persistence of rubella antibody beyond 6 months of age; in all, 21 samples were taken. Eight of the babies were sampled at birth or within 1 month of birth; of these eight, one was sampled again at 6 weeks of age, a second again at 2 months, and a third again at 11 months. From the remaining six infants eight serum samples were collected at 3-6 months of age and further samples were taken from one of these infants at 9 and 11 months of age.

Group 2 consisted of 17 babies with symptoms suggestive of congenital rubella infection, including jaundice (five cases), purpura (five cases), cataracts (two cases), congenital heart

Received 2 Feb. 1978; accepted 24 Feb. 1978.

* Present address: Department of Medical Microbiology, King's College Hospital Medical School, Denmark Hill, London SE5 8RX.

J. MED. MICROBIOL.-VOL. 11 (1978) 
disease (one case), microcephaly (one case) and microphthalmia (one case). A serum sample was taken from each baby at birth or within 6 weeks of birth. Unfortunately, virus isolation was not attempted in any of these infants and a later sample was obtained from only one, an infant aged 10 months.

Group 3 consisted of six apparently healthy babies whose mothers had rubella, confirmed by laboratory tests, during the first 4 months of pregnancy. A serum sample was collected from each, 10-16 weeks after birth. Five of the babies had obviously escaped infection as they failed to show the presence of rubella IgG antibody when retested at 13-60 months of age; a second serum sample could not be obtained from the sixth infant but he was healthy at 4 years of age.

The 21 samples from the first group of infants were processed for IgM antibody testing by both sucrose density-gradient centrifugation and gel filtration; the 23 samples from the second and third groups were processed only by the former method.

Rubella antibody techniques. To avoid the possible occurrence of false-positive results (Pattison, Mace and Dane, 1976), sera were not heat-inactivated. Before gel filtration through Sephadex G-200, as previously described by Pattison and Mace (1975), the sera were treated with heparin and manganous chloride to remove non-specific inhibitors of haemagglutination (Cooper et al., 1969); the initial volume of pretreated serum for gel filtration was $0.4-0.5 \mathrm{ml}$, and the peak IgM-containing fraction was collected as a 4-ml volume.

Sucrose density-gradient centrifugation was carried out by the method of CradockWatson et al. (1976); the starting volume of serum was $0.25-0.3 \mathrm{ml}$, and the peak IgM fraction was collected as a $0.6-\mathrm{ml}$ volume. The sera were not pretreated to remove lipoprotein inhibitors as these remain at the top of the gradient during centrifugation. However, because Al-Nakib, Best and Banatvala (1974) have reported that other non-specific inhibitors, of unknown type, may be deposited with the $\operatorname{IgM}$ and give false-positive results in the HI test (long method), several sera were also fractionated after treatment with heparin and manganous chloride to remove any such inhibitor.

$\mathrm{HI}$ tests were performed in microplates with 4 units of haemagglutinin; haemagglutinin and antibody-containing fractions were incubated either overnight at $4{ }^{\circ} \mathrm{C}$ (long method) or for $1 \mathrm{~h}$ at room temperature (short method) before adding erythrocytes from day-old chicks. Some density-gradient fractions were also tested after treatment with 2-mercaptoethanol (2ME) to destroy IgM (Caul, Smyth and Clarke, 1974). Indirect immunofluorescence tests for IgM and IgG antibodies were carried out as described by Cradock-Watson, Bourne and Vandervelde (1972).

\section{RESULTS}

\section{Serum samples from group 1 infants}

The results of the six tests for IgM antibody on the 14 infants with confirmed congenital rubella are illustrated in the table. Immunofluorescence testing of density-gradient fractions gave positive results with all 18 sera collected from the 14 infants during the first 6 months of life. The HI test (long method) gave positive results with 16 of the 18 sera, but with the remaining two, from infants aged 6 and 13 weeks, it gave negative results; one of these two infants had previously been positive at the age of 1 day. The HI test (short method) failed to detect antibody in a further six sera, obtained from four infants at or shortly after birth, and from two aged 6 weeks to 4 months. Gel filtration was generally less successful than sucrose density-gradient centrifugation, immunofluorescence demonstrating IgM antibody in only 13 of the 18 sera and the HI test in considerably fewer, especially when the short method was used. The three sera collected at 9-11 months of age, from two previously positive infants, were negative for antibody by all six tests. 
TABLE

Sensitivity of the immunofuorescence test and of the haemagglutination-inhibition (HI) test (long-and short-incubation methods) for the detection of rubella-specific IgM antibody in sucrose density-gradient and gel-filtration fractions of 21 sera from 14 infants (group 1) with congenital rubella

\begin{tabular}{|c|c|c|c|c|c|c|c|c|}
\hline \multirow{4}{*}{$\begin{array}{l}\text { Age of } \\
\text { infants }\end{array}$} & \multirow{4}{*}{$\begin{array}{c}\text { Number } \\
\text { of } \\
\text { infants }\end{array}$} & \multirow{4}{*}{$\begin{array}{l}\text { Number } \\
\text { of sera } \\
\text { examined }\end{array}$} & \multicolumn{6}{|c|}{ Number (and $\%$ ) of sera in which specific IgM antibody was detectable in } \\
\hline & & & \multicolumn{3}{|c|}{ density-gradient fractions by } & \multicolumn{3}{|c|}{ gel-filtration fractions by } \\
\hline & & & \multirow[b]{2}{*}{ immunofluorescence } & \multicolumn{2}{|c|}{ HI } & \multirow[b]{2}{*}{ immunofluorescence } & \multicolumn{2}{|c|}{ HI } \\
\hline & & & & $\begin{array}{l}\text { long } \\
\text { method }\end{array}$ & $\begin{array}{l}\text { short } \\
\text { method }\end{array}$ & & $\begin{array}{c}\text { long } \\
\text { method }\end{array}$ & $\begin{array}{l}\text { short } \\
\text { method }\end{array}$ \\
\hline $\begin{array}{l}<1 \text { month } \\
6 \text { weeks- } \\
6 \text { months }\end{array}$ & $\begin{array}{l}8 \\
8\end{array}$ & $\begin{array}{r}8 \\
10\end{array}$ & $\begin{array}{r}8(100) \\
10(100)\end{array}$ & $\begin{array}{l}8(100) \\
8(80)\end{array}$ & $\begin{array}{l}4(50) \\
6(60)\end{array}$ & $\begin{array}{l}8(100) \\
5(50)\end{array}$ & $\begin{array}{l}5(62 \cdot 5) \\
4(40)\end{array}$ & $\begin{array}{l}3(37 \cdot 5) \\
1(12 \cdot 5)\end{array}$ \\
\hline $\begin{array}{l}6 \text { months } \\
9-11 \text { months }\end{array}$ & 3 & 3 & 0 & 0 & 0 & 0 & 0 & 0 \\
\hline Total & $14 *$ & 21 & $18(86)$ & $16(76)$ & $10(48)$ & $13(62)$ & $9(43)$ & $4(19)$ \\
\hline
\end{tabular}

* From four of the infants, sera were collected in more than one of the age ranges.

The density gradient-immunofluorescence technique therefore detected IgM antibody in all 14 infants, the density gradient-HI technique (long method) in $13(93 \%)$, and the gel filtration-immunofluorescence technique in $12(86 \%)$. The density gradient-HI technique (short method), the gel filtration-HI technique (long method) and the gel filtration-HI technique (short method) were much less sensitive, demonstrating antibody in only $9(64 \%), 8(57 \%)$ and 4 $(29 \%)$ infants, respectively.

Fig. 1 illustrates the titres of IgM antibody of the 21 sera fractionated by sucrose density-gradient centrifugation and then tested by the immunofluorescence test and by the HI test (long and short methods). With the 18 sera containing IgM antibody, the immunofluorescence test was invariably more sensitive than the HI test (short method). It was also more sensitive than the HI test (long method), giving titres 2-256-fold higher in 15 of the 18 sera; in one serum the same titre was obtained by both methods, and in two the HI test actually gave 4-fold higher titres. Essentially similar results were obtained with gel-filtration fractions (fig. 2), the immunofluorescence test generally giving 2-16-fold higher titres than the HI test (long method).

To investigate the possibility that the higher IgM titres obtained by the HI test (long method) were due to the presence of non-specific inhibitors, five sera with relatively high titres (8-64) in their IgM fractions were pretreated with heparin and manganous chloride before fractionation on sucrose, and reexamined. With two of the sera, which had previously shown higher titres by the $\mathrm{HI}$ test (long method) than by immunofluorescence, HI titres were unchanged; with another two, collected from a single patient at different intervals after birth, the titres were reduced by $50 \%$, and with the fifth serum the titre was reduced by $75 \%$. Some of the $\mathrm{HI}$ activity in the untreated serum fractions may therefore have been due to non-specific inhibitors, but unfortunately there was insufficient serum for testing treated and untreated serum fractions simultaneously. On the other hand, the residual HI activity in the fractions from the 


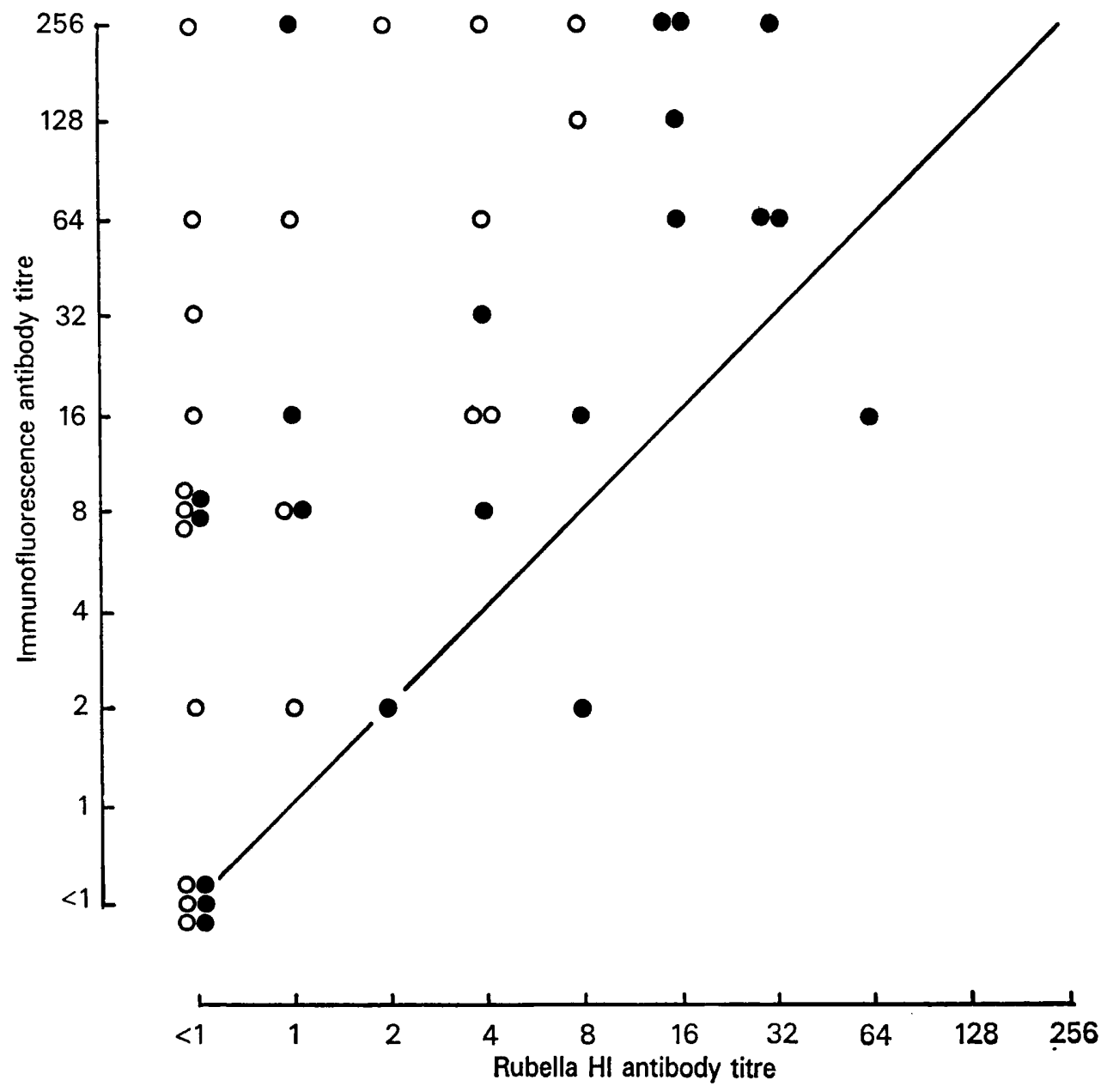

FIG. 1.-Comparison of the IgM antibody titres in 21 sera from 14 infants (group 1) with congenital rubella, measured in sucrose density-gradient fractions by immunofluorescence and by the longincubation (O) or short-incubation (O) $\mathrm{HI}$ techniques.

five pretreated sera was completely eliminated by $2 \mathrm{ME}$ confirming that it was due to IgM antibody.

Whichever method was used for titrating antibody, higher titres were always obtained in the sucrose density-gradient fractions than in the gel filtration fractions-as much as 64-fold higher when immunofluorescence was used, and as much as 8-fold higher when the HI test (long method) was used. With both kinds of fractions, the HI test (long method) almost always gave higher titres (2-32-fold) than the HI test (short method); the only exception was a serum fractionated on sucrose that gave the very low titre of 1 by both HI tests.

\section{Serum samples from group-2 infants}

IgM antibody could not be detected by immunofluorescence in any of the 17 infants with clinically suspected congenital rubella. In one, a low titre 


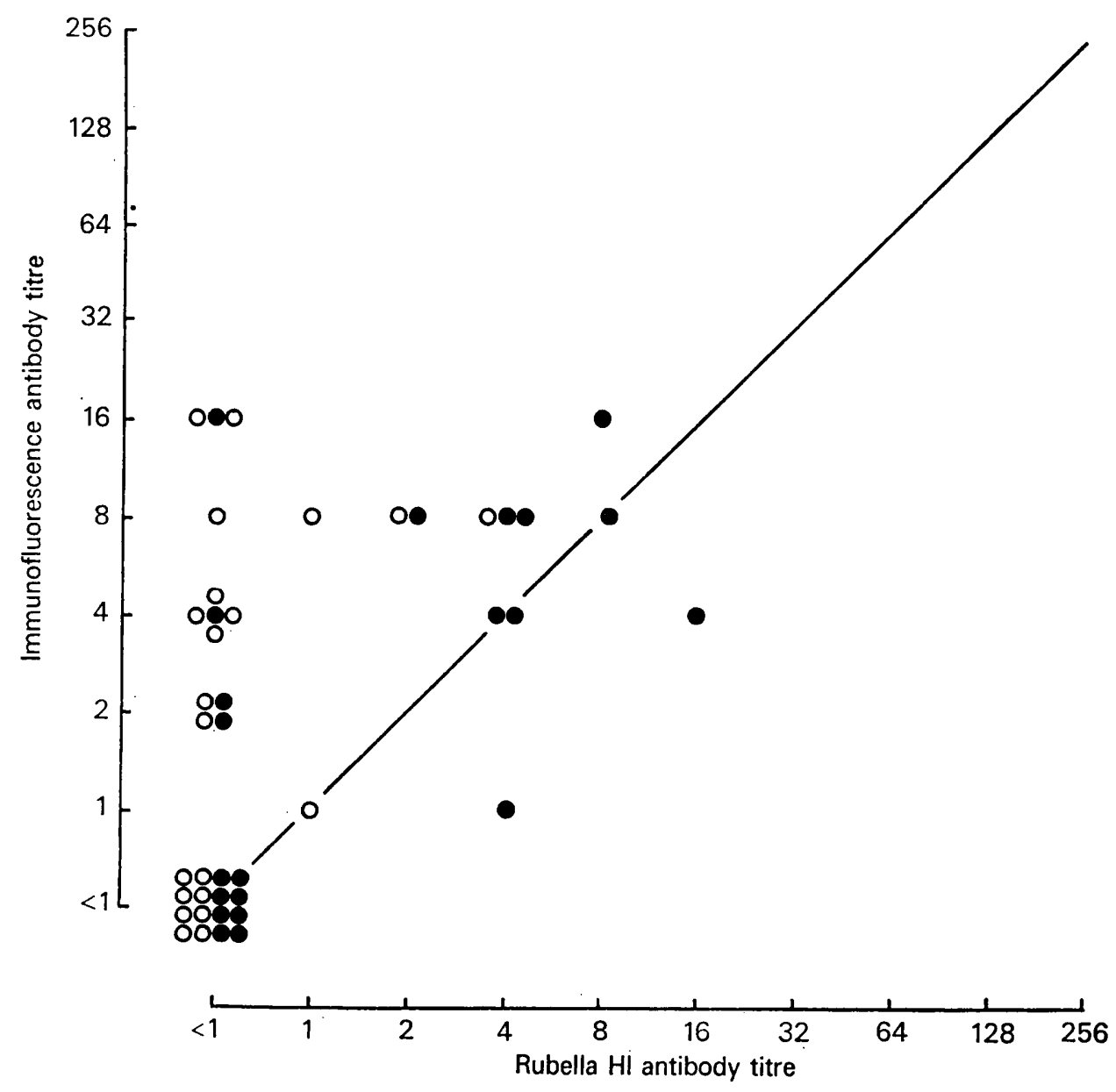

Fig. 2. - Comparison of the IgM antibody titres in 21 sera from 14 infants (group 1) with congenital rubella, measured in Sephadex G-200 gel filtration fractions by immunofluorescence and by the long-incubation (๑) or short-incubation (O) $\mathrm{HI}$ techniques.

(1.5) was obtained only by the HI test (long method). There was insufficient serum from this infant for further testing. A second infant, with thrombocytopenic purpura, gave titres of 8 and 2 by the long and short methods, respectively; this activity was abolished by treatment with $2 \mathrm{ME}$ but not by pretreatment with heparin and manganous chloride. On the other hand, rubella infection in this infant could be excluded as at 10 months of age rubella IgG antibody was absent.

Serum samples from group-3 infants

Immunofluorescence also failed to demonstrate IgM antibody in any of the six healthy infants born to mothers who had experienced rubella in early 
pregnancy. In only one was a low HI titre (1) obtained by both the long and short methods of the HI test; there was insufficient serum for testing to exclude non-specific inhibitors, but rubella infection could be excluded by the absence of IgG antibody in a further specimen of serum collected at 4 years of age.

\section{Discussion}

The procedure of fractionating serum by gel filtration and testing the IgMcontaining fractions for specific antibody by the HI test (long method) has been shown to be reliable for the diagnosis of rubella in adults (Pattison and Dane, 1975). The present results show that this is not so for the diagnosis of congenital infection; specific IgM antibody was detected in only 8 out of $14(57 \%)$ confirmed cases. This was without doubt due largely to the considerable dilution of antibody that occurs during gel filtration. Bellanti et al. (1965) overcame this difficulty by concentrating the fractions 10 -fold or more before testing for neutralising antibody. Unfortunately, concentration of sera intended for examination by the $\mathrm{HI}$ test may result in high levels of the residual non-specific inhibitors that may contaminate the IgM fractions. IgM can of course be distinguished by its sensitivity to $2 \mathrm{ME}$, but when the antibody titre is low it may be difficult to demonstrate a significant reduction.

Density-gradient centrifugation results in relatively little dilution of antibody in the test fractions. This advantage is lost, however, with the HI test (short method); IgM antibody was detected in only 9 of the 14 cases (64\%), this result being only marginally better than that $(57 \%)$ with the gel filtration-HI test (long method). However, when the long method was applied to densitygradient fractions, IgM antibody was found in 13 of the 14 cases $(93 \%)$.

Unfortunately the HI test (long method) did not prove to be as sensitive as the indirect immunofluorescence test; with few exceptions, fluorescence antibody titres were higher. The difference between the immunofluorescence and HI titres was very variable, ranging from 2-256-fold, perhaps because of the subjective error involved in reading fluorescence antibody end-points. Nevertheless, immunofluorescence was undoubtedly more sensitive than the HI test (long method) and, when applied to density-gradient fractions, gave the best results; IgM antibody was detected in all 14 cases of confirmed congenital rubella.

The immunofluorescence technique is not widely used for detecting rubella antibodies and most laboratories probably find it more practicable to carry out HI tests (long method) with density-gradient fractions, the simpler techniques compensating for the slight loss of sensitivity; only low titres of IgM antibody are likely to be missed. It must be emphasised, however, that the HI test (long method), besides being less sensitive than immunofluorescence, is also less specific and may be affected by inhibitors other than IgM antibody. The inhibitor described by Al-Nakib et al. (1974) can be removed by pretreatment with heparin and manganous chloride, and we recommend the routine use of this procedure in HI tests for rubella IgM antibody. However, there may be 
other non-specific inhibitors with a density similar to that of the heavy IgMcontaining fractions. This might account for the low titres of $\mathrm{HI}$ activity that were detected in the infants with suspected rubella infection, but in whom simultaneous immunofluorescence tests were negative and rubella infection could not subsequently be confirmed; this activity could easily have been mistaken for IgM antibody activity as, in the single serum sample investigated, the $\mathrm{HI}$ activity was destroyed by $2 \mathrm{ME}$ and was unaffected by heparin and manganous chloride. Caution should therefore be exercised in interpreting the results obtained by sucrose density-gradient centrifugation and the $\mathrm{HI}$ test (long method).

\section{SUMMARY}

Serum specimens from 14 infants with congenital rubella were examined for specific IgM antibody by six different methods. IgM-containing fractions were separated either by sucrose density-gradient centrifugation or by gel filtration through Sephadex G-200, and were then tested by the indirect immunofluorescence technique and by the haemagglutination-inhibition (HI) test (long- and short-incubation methods).

Immunofluorescence staining of density-gradient fractions detected specific IgM in all 14 infants. The HI test (long method), applied to density-gradient fractions, was almost as sensitive, detecting antibody in 13 infants; the short method was less sensitive. The gel-filtration technique proved to be generally less satisfactory than sucrose density-gradient centrifugation.

Evidence was obtained for the occurrence of as yet unclassified non-specific inhibitors in the serum of some infants. These inhibitors were deposited with the IgM on sucrose-density gradients and they could have been mistaken for rubella-specific IgM antibody, particularly in the HI test (long method).

\section{REFERENCES}

Al-Nakib, W., BeST, J. M. AND Banatvala, J. E. 1974. Rubella-specific IgM and a new inhibitor. Br. med. J., 3, 579.

Bellanti, J. A., Artenstein, M. S., Olson, L. C., Buescher, E. L., Luhrs, C. E. AND MilSteAD, K. L. 1965 . Congenital rubella; clinicopathologic, virologic, and immunologic studies. Am.J. Dis. Child., 110, 464.

Caul, E. O., Smyth, G. W. and Clarke, S. K. R. 1974. A simplified method for the detection of rubella-specific IgM employing sucrose density fractionation and 2-mercaptoethanol. J. Hyg., Camb., 73, 329.

Cooper, L. Z., MatTers, B., Rosenblum, J. K. AND Krugman, S. 1969. Experience with a modified rubella hemagglutination inhibition antibody test. J. Am. med. Ass., 207, 89.

Cradock-Watson, J. E., Bourne, M. S. AND VANDERvelde, E. M. 1972. IgG, IgA and IgM responses in acute rubella determined by the immunofluorescent technique. J. Hyg., Camb., 70, 473.

Cradock-Watson, J. E., Ridehalgh, M. K. S. and Chantler, S. 1976. Specific immunoglobulins in infants with the congenital rubella syndrome. J. Hyg., Camb., 76, 109.

Pattison, J. R. AND Dane, D. S. 1975. The routine serological investigation of cases and contacts of rubella. J. Hyg., Camb., 75, 91.

Pattison, J. R. AND Mace, J. E. 1975. The detection of specific IgM antibodies following infection with rubella virus. J. clin. Path., 28, 377. 
Pattison, J. R., Mace, J. E. AND Dane, D. S. 1976. The detection and avoidance of falsepositive reactions in tests for rubella-specific IgM. J. med. Microbiol., 9, 355.

Vesikari, T., Vaheri, A., PetTay, O. and Kunnas, M. 1969. Congenital rubella: immune response of the neonate and diagnosis by demonstration of specific IgM antibodies. J. Pediat., 75, 658. 